\title{
Ensino, pesquisa e extensão na formação docente: memórias vivenciadas no estágio supervisionado
}

\author{
Education, research and extension in teacher training: lived in \\ memories supervised internship
}

\author{
Vilmar José Borges* \\ Universidade Federal do Espírito Santo \\ Sônia Maria dos Santos** \\ Universidade Federal de Uberlândia
}

Resumo O presente artigo visa socializar reflexões sobre processos de formação/ ação docente, tomando por referência a narrativa de professores atuantes na Educação Básica sobre metodologias de ensino desenvolvidas no cotidiano da sala de aula e consideradas positivas. Retrata pesquisa apoiada na história oral, desenvolvida por dois professores universitários, mediante a necessidade de superação da visão acrítica observada na maioria dos "futuros professores" relacionada ao Estágio Supervisionado. Os estagiários realizaram entrevistas orais com os professores atuantes em diferentes níveis e áreas do saber, acerca das metodologias de ensino; exposição de pôsteres divulgando as mesmas; e, ainda, realização de oficinas pedagógicas adaptando as diferentes metodologias à conteúdos da geografia escolar. A experiência metodológica se mostrou enriquecedora tanto para os professores, quanto para os alunos envolvidos.

PALAVRAS-CHAVE: Estágio supervisionado; História oral; Formação docente; Pesquisa e extensão.

Abstract This article aims to socialize reflections on teacher training processes, taking as reference the narratives of teachers working in Basic Education on teaching methodologies developed in the daily classroom and considered positive. It portrays research based on oral history, developed by two university professors, through the need to overcome the uncritical view observed in the majority of "future teachers" related to the Supervised Internship. The trainees conducted oral interviews with teachers at different levels and areas of knowledge about teaching methodologies; exposing posters advertising the same; and also the realization of pedagogical workshops adapting the different methodologies to the contents of the school geography. The methodological experience was enriching both for the teachers and for the students involved.

KEYWORDS: Supervised internship; Oral history; Teacher training; Research and extension. 
O presente artigo tem como referência a memória de dois professores universitários, preocupados com os modos de pensar e fazer o Estágio Supervisionado, nos cursos de Licenciatura em Geografia da Universidade Federal do Espírito Santo e Pedagogia na Universidade Federal de Uberlândia. Trata-se, pois, de experiências vivenciadas na Prática de Ensino e implementadas como alternativa para superar a visão mecânica e acrítica encontrada na grande maioria dos "futuros professores" acerca do Estágio Supervisionado.

Ao iniciar suas atividades como professor supervisor de Estágio no Curso de Licenciatura em Geografia, o professor da Universidade Federal do Espírito Santo elaborou e aplicou um questionário-diagnóstico. $\mathrm{O}$ objetivo foi mapear a visão dos "futuros professores" acerca da disciplina, suas perspectivas, seus limites e possibilidades. A tabulação dos dados desvelou que a grande maioria dos estudantes concebe a atividade docente apenas como o momento da prática em sala de aula. Como consequência, concebe também o Estágio Supervisionado como disciplina que deveria propiciar a eles a inserção no espaço da sala de aula, preferencialmente de alguma escola pública do ensino fundamental e/ou médio para ministrar algumas aulas e, assim, cumprirem com uma mera formalidade burocrática.

Essa crença sobre o papel e o lugar do Estágio também foi observada nas percepções das alunas do curso de Pedagogia, conforme vivencias da professora da Universidade Federal de Uberlândia. Neste contexto de insatisfação com as concepções dos "futuros professores", os dois docentes, em um trabalho integrado, buscaram auxílio teórico para analisar e propor a superação desta problemática.

Segundo Pimenta e Lima (2004), o Estágio Supervisionado pode e deve se constituir em "campo de conhecimento que se produz na interação entre cursos de formação e o campo social no qual se desenvolvem as práticas educativas" (p.29). Esse campo social pode se materializar nas escolas de ensino fundamental e médio, envolvendo seus sujeitos (docentes, discentes, gestores, especialistas, etc.) e relações que ali se estabelecem e que compõem o seu cotidiano.

Para as autoras, é possível categorizar o Estágio Supervisionado em três grupos. Um grupo concebe o Estágio como prática de imitação de modelos, onde os alunos estagiários observam e imitam. Outro grupo concebe o Estágio como prática de instrumentalização técnica. Nesse sentido, o papel do professor é entendido a partir da perspectiva do paradigma de formação conservador, da racionalidade técnicocientífica, reduzindo a atividade docente à mera técnica. O professor é considerado, então, como uma máquina executora de tarefas pré-estabelecidas. Portanto, nessa visão, o importante seria instrumentalizar os "futuros professores" com técnicas de ensino, concebendo-o como mero reprodutor mecânico e acrítico de tais técnicas.

Existe ainda um terceiro grupo, no qual acreditamos e buscamos fazer parte, que entende o Estágio como momento de superação da separação entre teoria e prática, entendendo-o como pesquisa e a pesquisa como estágio. Trabalhar o Estágio Supervisionado nessa perspectiva exige voltar nossos olhares para a internalidade do processo educativo, conforme sugere Nóvoa (1992). Significa buscar compreender/ 
apreender a complexa rede de relações que se estabelecem no interior desse processo, no qual o professor não é apenas uma peça decorativa ou complementar, como se fosse uma engrenagem executora de tarefas, de técnicas prescritas nos gabinetes educacionais e nos manuais didáticos.

Por esse motivo, é preciso considerar que a prática pedagógica do docente se concretiza na materialização de sonhos, crenças, representações sobre a educação e o ensino. As diretrizes, os parâmetros e as propostas recebidas, prontas e acabadas, como caminhos a serem seguidos, fazem parte do território no qual se movem os sujeitos, seus saberes e seus fazeres.

Assim, nossa proposta foi a de estruturar um projeto de Ensino de Estágio Supervisionado voltado para a busca da compreensão da prática pedagógica do docente, tentando compreender as expectativas, a reflexão de sua prática, dos resultados, dos idealizados e do realizado, dos sonhos, das decepções e das utopias.

Para tanto, o referido projeto foi construído na perspectiva de se constituir como um espaço de produção de conhecimento sobre a prática pedagógica desenvolvida no cotidiano da escola pública, no intuito de possibilitar aos "futuros professores" uma maior aproximação da realidade dessas escolas, bem como das condições de trabalho de seus docentes. Essa aproximação permitiu aos graduandos uma melhor compreensão dos desafios que deverão enfrentar no mundo do trabalho, de forma crítica e consciente, e também se comprometendo com o projeto de democratização da escola pública fundamental.

A intenção principal do projeto foi a de mudar a ideia simplista de que o Estágio deva ser restrito às "atividades programadas a priori”. A defesa foi a de que a sua orientação pudesse emergir "das discussões entre educador x educando, no cotidiano da sala de aula, da escola" (PICONEZ, 1994, p.17). O que implica dizer que o estágio não pode se prender aos limites de uma sala de aula, e sim que a escola como um todo deve se tornar um espaço para a prática. Tornou-se, então, necessário criar ações coletivas de embates e debates, que visassem superar as concepções de Estágio, entendido apenas como função burocrática, ou como contemplação de modelos.

Nesse sentido, reafirmamos nossa concepção do Estágio Supervisionado como uma disciplina que deve permitir um contato real entre os saberes (GAUTHIER, 1998; TARDIF, 2000) que estão sendo produzidos nas academias e os saberes que estão sendo mobilizados, (re)construídos e (re)produzidos dentro da comunidade escolar. Diante da distorcida e supérflua concepção da disciplina, presente nos discursos e perspectivas dos discentes tanto da Pedagogia como da Geografia, deparamo-nos com o desafio de imprimir praticidade, criticidade e objetividade à mesma. Buscamos alternativas que possibilitassem um melhor aproveitamento da prática, conforme proposta do projeto de ensino, perseguindo o pressuposto de que um dos principais objetivos da disciplina Estágio Supervisionado é o de colocar os "futuros professores" em contato direto com a realidade do campo escolar, seu provável futuro campo de trabalho.

Lima (2001) também defende ser o Estágio um importante momento de formação e, por isso, defende a necessidade do Estágio ser investigado e considerado um campo de conhecimento. 
[...] é preciso reconhecer o Estágio como um campo de conhecimento a ser investigado, e não como prática apenas, mas com sensibilidade pedagógica capaz de ver a parte e nela assumir a postura e o compromisso de compreender o todo. Trata-se da aprendizagem pedagógica de ler nas entrelinhas da sala de aula, do Estágio, da escola, da realidade da vida... (LIMA, 2001, p.70).

Concordamos com a autora e vemos no Estágio Supervisionado uma grande possibilidade de contribuição para que a formação inicial do docente não conceba o exercício da profissão como apenas o momento do estar na sala de aula, desenvolvendo o ensino, mas que também requer prática da pesquisa e da extensão. Diante disso, nosso desafio foi o de buscar alternativas que possibilitassem um amplo envolvimento discente com o cotidiano escolar e a prática docente. Tais buscas têm se consolidado no oferecimento de projetos de ensino/extensão, envolvendo os alunos estagiários e criando possibilidades do estabelecimento de um elo de ligação entre as Universidades e as escolas de ensino fundamental e médio da região da Grande Vitória-ES e de Uberlândia-MG.

Trata-se, portanto, de um projeto que almejou a convergência de atividades de ensino, pesquisa e extensão na formação docente, sendo esta caracterizada como um espaço propício para a vivência da reflexão sobre a sua prática como possibilidade de aprimoramento da práxis pedagógica (GIROUX, 1997; NÓVOA; 1995, SCHÖN, 2000; LARROSA, 1995; BENJAMIN, 1985; BOM MEHEY, 1996; FOERSTE, 2005).

Para o desenvolvimento das atividades práticas, foi apresentada para os alunos estagiários uma proposta de trabalho que teve como objetivo geral contribuir para uma possível aproximação das Universidades com as Escolas do Ensino Fundamental e Médio. Essa aproximação se deu pela socialização de reflexões acerca de alternativas metodológicas de ensino-aprendizagem, desenvolvidas e implementadas no cotidiano da sala de aula e narradas por professores como positivas no desenvolvimento de suas respectivas funções.

Os objetivos específicos foram: a) criar espaço que possibilitasse aos licenciandos reflexões críticas acerca de práticas pedagógicas desenvolvidas e/ou adaptadas na realidade escolar; b) dar retorno, como contrapartida das Universidades, aos professores colaboradores e às escolas parceiras na realização das atividades do Estágio Supervisionado; c) desmistificar, junto aos participantes, a ideia de que a atividade docente só se efetiva no espaço da sala de aula.

Nesse sentido, paralelo e associado ao desenvolvimento da disciplina Estágio Supervisionado, iniciamos as atividades da pesquisa. No ensino, buscamos discutir e analisar textos que subsidiassem os debates sobre os saberes necessários ao exercício da profissão docente (GAUTHIER e TARDIF, 1997; SHÖN, 2000), seu processo de profissionalização (ARAÚJO, 2000); e a construção de sua identidade profissional (LACERDA, 1996; NÓVOA, 1995, VASCONCELOS, 2000). Na pesquisa, utilizamos como caminho metodológico os aportes teóricos da História Oral (BOM MEIHY, 1996; QUEIROZ, 1998; SANTOS, 2007, 2010). 
Segundo Bom Meihy,

História oral é um recurso moderno usado para a elaboração de documentos, arquivamento e estudos referentes à vida social de pessoas. Ela é sempre uma história do tempo presente e também conhecida por história viva. (...) a história oral se apresenta como forma de captação de experiências de pessoas dispostas a falar sobre aspectos de sua vida mantendo um compromisso com o contexto social. (1996, p.13).

Atualmente é possível reconhecer três tendências nas pesquisas que utilizam a história oral como abordagem metodológica: a história oral de vida, a história oral temática e a tradição oral. A abordagem escolhida para o nosso estudo apoiou-se na modalidade da história oral temática, privilegiando a coleta de depoimentos por meio de entrevistas orais, realizadas com os professores atuantes nos níveis Fundamental, Médio e Superior, das redes pública e particular de ensino da Grande Vitória-ES e em Uberlândia-MG, em diferentes áreas do saber.

Optou-se pela história oral temática, pois esta abordagem parte de um tema específico, preestabelecido e, portanto, a objetividade é mais direta. Visto que, conforme Bom Meihy,

Dado seu caráter específico, a história oral temática tem características bem diferentes da história oral de vida. Detalhes da história pessoal do narrador apenas interessam na medida em que revelam aspectos úteis à informação temática central (1996, p. 41).

Nesse sentido, cada aluno(a) matriculado(a) na disciplina Estágio Supervisionado entrou em contato com um(a) professor(a) atuante no ensino fundamental, médio e/ou superior, da rede particular ou pública da região metropolitana da Grande Vitória-ES e de Uberlândia-MG para agendar as respectivas entrevistas. O objetivo das entrevistas foi obter narrativas acerca de metodologias de ensino desenvolvidas e/ ou adaptadas e implementadas, pelo(a)s mesmo(a)s, no cotidiano da sala de aula, cujos resultados de ensino-aprendizagem julgassem positivos.

Assim, em conformidade com os objetivos da investigação e os pressupostos metodológicos da História Oral Temática, procedemos à elaboração de um roteiro temático de entrevista, composto de questões cuja finalidade era estimular as narrativas dos docentes parceiros acerca da temática estabelecida. $\mathrm{O}$ roteiro foi composto pelas seguintes questões: nome completo do(a) professor(a) colaborador(a), ano, instituição e curso de graduação; cursos de pós-graduação; tempo de exercício no magistério. E ainda pelas seguintes perguntas: o que é uma boa aula para você? O que você faz para atrair a atenção de seus alunos para suas aulas? Descreva, passo a passo, uma estratégia/ técnica de ensino que você tenha implementado em sala de aula e que julgou positiva.

Os "futuros professores" foram orientados a contatarem os professores colaboradores para exposição dos objetivos do trabalho, solicitando a concessão das respectivas entrevistas. Para isso, agendaram com os colaboradores o local e a data para a realização das entrevistas, que foram todas gravadas. Conforme Bom Meihy (1996), em pesquisas que utilizam a abordagem metodológica baseada na história oral temá- 
tica, o uso da documentação oral equivale às fontes escritas. Assim, um dos principais instrumentos de coleta de dados é a entrevista oral gravada, que incide sobre um assunto específico e preestabelecido, utilizando, para isso, a narrativa.

Realizadas as entrevistas, os estagiários procederam à transcrição das mesmas, devolvendo-as aos respectivos colaboradores para conferirem, acrescentarem e/ou suprimirem trechos e/ou frases e informações que julgassem necessárias, bem como para autorizarem a utilização das respectivas narrativas.

Após a etapa da transcrição e textualização das entrevistas, os estagiários, sob orientação dos professores supervisores, apropriaram-se das narrativas, mais especificamente dos depoimentos relacionados às metodologias de ensino desenvolvidas e/ou implementadas por eles. Esse exercício de apropriação das narrativas foi direcionado no sentido de extrair informações básicas para elaboração de pôsteres, com vistas a socializar as experiências narradas, contribuindo assim para que as mesmas não ficassem confinadas aos segredos das salas de aula.

Gauthier (1998) nos adverte que, embora o professor viva as mais diversas experiências, das quais retira grande proveito, quando não socializadas, permanecem confinadas aos segredos da sala de aula. O confinamento de experiências positivas nas fronteiras da sala de aula impede uma reflexão mais crítica sobre as mesmas e, assim, deixa-se de fazer o elo de ligação e mútua retroalimentação da prática/teoria/prática. Práticas docentes positivas, quando experienciadas, debatidas e socializadas contribuem para a superação de inúmeras dificuldades de docentes, principalmente daqueles em início de carreira.

Diante de tais convicções e buscando ampliar as possibilidades de uma maximização das metodologias de ensino narradas, no momento de sua socialização, os "futuros professores" foram orientados a extrair das referidas narrativas as seguintes categorias que constituiriam os pôsteres a serem expostos: a) identificação, onde deveria constar o título do pôster a ser divulgado, sugerindo aos licenciandos utilizarem de bastante criatividade, sem perder de vista a ligação do título com a metodologia narrada; b) objetivos, onde os licenciandos deveriam analisar as narrativas e extrair das mesmas um objetivo geral como também objetivos específicos trabalhados pelos colaboradores na implementação da metodologia; c) metodologia, onde deveria constar um resumo-síntese da metodologia em divulgação; d) procedimentos, onde deveriam ser indicados o passo-a-passo, ou seja, os procedimentos necessários para a implementação da metodologia; e, e) bibliografia, quando além da fonte de sustentação da metodologia de pesquisa, os "futuros professores" estariam divulgando também as informações relativas aos depoentes que se dispuseram a narrar as suas experiências. Destacamos que todos os professores colaboradores concordaram com a divulgação de seus respectivos nomes, não sendo, portanto, necessário utilizar do recurso de invisibilidade.

Nesse sentido, foram confeccionados pôsteres, divulgando as mais diversificadas metodologias de ensino, narradas por professores de diversas áreas do saber e atuantes nos diferentes níveis e sistemas de ensino, sendo assim possível perceber as 
inúmeras possibilidades de integração de conteúdos e de se desenvolver trabalhos inter e transdisciplinares, na busca pela melhoria da qualidade do ensino, propiciadas por propostas de ensino semelhantes à aqui narrada.

Visando uma mais ampla socialização das metodologias de ensino, foram organizadas duas exposições dos pôsteres confeccionados, com divulgação e abertura da mesma tanto ao público interno (docentes e discentes das licenciaturas da Universidade Federal do Espírito Santo e da Faculdade de Educação da Universidade Federal de Uberlândia) quanto externo (professores da rede pública e particular de ensino da Grande Vitória-ES e do município de Uberlândia, interior de Minas Gerais). Ressaltamos que os "futuros professores" envolveram-se também com o momento de preparação, organização e divulgação da atividade de extensão, caracterizada pela exposição dos pôsteres, vivenciando, portanto, faces das atividades de ensino, de pesquisa e de extensão, presentes no cotidiano do professor. Durante o período de exposição dos pôsteres, a exemplo dos grandes congressos, os "futuros professores" ficaram ao lado dos respectivos trabalhos prestando esclarecimentos gerais ao público visitante.

Conforme explicitado anteriormente, a etapa de elaboração e exposição dos pôsteres visou uma socialização das diferentes metodologias de ensino, gestadas e/ou adaptadas pelos docentes colaboradores, no exercício de suas respectivas funções. Esse exercício reflexivo, além de contribuir para uma aproximação Universidade/Escolas de Ensino Fundamental e Médio, também possibilitou aos "futuros professores" reflexões críticas acerca de práticas pedagógicas desenvolvidas e/ou adaptadas na realidade escolar, além de dar retorno, como contrapartida da Universidade, aos professores colaboradores e às escolas parceiras na realização das atividades do Estágio Supervisionado. Retorno esse materializado principalmente pela possibilidade de participação nas atividades de Extensão.

Apoiados no projeto e visando atender a uma das especificidades do Estágio Supervisionado, que é a de instrumentalizar os "futuros professores" para o exercício efetivo da função docente, possibilitando momentos de experienciar não só a observação como também a intervenção em atividades de prática de ensino, o "trabalhar aulas" propriamente dito, partimos para um segundo momento de nosso trabalho.

Nessa etapa, propusemos aos "futuros professores" que, em posse das diferentes metodologias de ensino com as quais tiveram contato na forma de pôster, buscassem a apropriação de uma dentre elas, para planejamento e execução de uma oficina pedagógica, adaptada a algum conteúdo específico do ensino de Geografia, no caso da Federal do Espírito Santo, e, no caso da Federal de Uberlândia, os "futuros professores" do curso de pedagogia foram orientados a pensarem no ensino de EJA (alfabetização e series iniciais do ensino fundamental).

A opção pela adoção do trabalho por esta metodologia alternativa de ensino se prendeu ao fato de entendermos a oficina pedagógica como uma metodologia de trabalho em grupo, caracterizada pela "construção coletiva de um saber, de análise da realidade, de confrontação e intercâmbio de experiências" (CANDAU, 1999, p.23), onde o saber não se constitui apenas no resultado final do processo de aprendizagem, mas também no processo de construção do conhecimento. 
Nesse sentido, reafirmamos que este artigo buscou revelar as práticas do processo vivenciado por dois professores que atuam um no Centro de Educação da Universidade Federal do Espírito Santo, curso de Licenciatura em Geografia e outra no Curso de Pedagogia da Faculdade de Educação da Universidade Federal de Uberlândia. Trata-se, portanto, de experiências testadas e implementadas no cotidiano do fazer Estágio Supervisionado e, dessa forma, pode-se afirmar a importância e relevância das mesmas, expressas nas manifestações dos "futuros professores" nos momentos das várias avaliações ocorridas ao longo do processo. Um desses momentos de avaliação das atividades ocorreu simultâneo à exposição dos pôsteres, quando, utilizando painéis integrados, colhemos depoimentos tanto dos estagiários quanto do público que visitou a exposição, onde encontramos manifestações de apoio e incentivo à continuidade da experiência narrada, destacando, inclusive, as várias possibilidades de aprendizagem propiciadas pela mesma.

Mediante a receptividade, tanto por parte dos "futuros professores" envolvidos com o projeto de ensino, quanto por outros profissionais que participaram das atividades extensionistas, a referida proposta foi implementada outras vezes, em anos subsequentes, na Universidade Federal do Espírito Santo, tendo, portanto, alcançado uma certa maturidade.

Ao final de cada proposta de ensino desenvolvida, foram colhidos depoimentos avaliativos dos estagiários envolvidos, sendo comum a ocorrência de avaliações positivas em todas as versões, conforme narrativas abaixo:

No geral, a disciplina Estágio Supervisionado tem sido muito instrutiva e interessante, ressaltando metodologias de ensino que servirão para toda uma vida acadêmica futura. As pesquisas, técnicas e observações utilizadas na disciplina permitiram o aprimoramento e o incremento de metodologias que normalmente são ministrados pelos professores observados e entrevistados, além da sua socialização e reflexão. (ENM, 2013)

Avalio como uma das disciplinas mais úteis que já fiz em todo o curso. Todas as atividades contribuíram diretamente em minha prática docente. Acredito ser um exemplo para várias outras disciplinas, que muitas vezes são excessivamente teóricas e completamente dissociadas da prática. (ATJ, 2013)

Dentro das propostas de aula do Estágio Supervisionado I, creio que as atividades que me trouxeram um melhor aproveitamento foram as de coleta de metodologias (através de entrevista com História Oral Temática) e posterior desenvolvimento de Pôsteres. Nestas atividades, houve a possibilidade de se colocar como pesquisador, professor e aluno, ainda que dentro da Universidade. (ICS, 2014)

A disciplina de Estágio Supervisionado I tem sido de suma importância para minha formação futura como profissional da educação. A partir dessa disciplina pude entender de forma mais clara o verdadeiro papel do professor, que muitos resumem como um simples profissional que reproduz as informações específicas que este se especializa. Mas muito mais que isso, o professor tem a responsabilidade de auxiliar na construção das gerações futuras. (JCS, 2014) 
Diante de manifestações como as expressas acima, acreditamos que com essa atividade prática, o aluno estagiário tenha a oportunidade de desenvolver reflexões acerca dos aspectos internos e externos à sala de aula, tanto de caráter intra quanto extramuros escolares, que influenciam direta e/ou indiretamente na práxis docente.

Nessa perspectiva, entende-se que a oferta de atividades de pesquisa e de extensão, juntamente com as atividades de ensino, como estratégia metodológica da disciplina Estágio Supervisionado, pode se constituir em uma experiência enriquecedora simultaneamente tanto para os professores, quanto para os alunos envolvidos.

Como culminância da proposta, os estagiários participantes da mesma encaminham ao professor supervisor, em arquivos eletrônicos, tanto os modelos dos pôsteres elaborados e expostos, quanto os planos das oficinas pedagógicas desenvolvidas. Os referidos arquivos eletrônicos foram condensados e reproduzidos em cds, e cópias dos mesmos foram entregues tanto para os estagiários quanto para os professores parceiros, ampliando-se, assim, o alcance da socialização das metodologias de ensino.

Acredita-se que ao possibilitar momentos de aprendizagem extra-curricular para ambas as categorias, com todas as prerrogativas que estão implícitas nessa possibilidade pedagógica, há ainda a prática dos princípios de ensino, de pesquisa e de extensão que caracterizam a existência da Universidade. É com esse espírito que estamos tentando contribuir.

Por fim, há que se registrar ainda que a partir dessa vivência e mediante a explicitação de inúmeras avaliações positivas, nasceu o projeto de pesquisa, nível de doutoramento, desenvolvido pelo professor supervisor da Universidade Federal do Espírito Santo, junto ao Programa de Doutorado em Educação Escolar da Universidade Estadual Paulista "Professor Júlio de Mesquita Filho" - Campus de Araraquara. De maneira semelhante à experiência aqui rememorada e ampliando o campo de pesquisa, o projeto de doutorado em questão visou ouvir e dar voz à professores supervisores e professores parceiros, vinculados às Instituições Federais de Ensino, da Região Sudeste do Brasil, a respeito de seus saberes e seus fazeres na realização do Estágio Supervisionado, na formação docente em Geografia.

\section{Referências}

ARAÚJO, José Carlos de S. As intencionalidades como diretrizes da práxis pedagógica. In: VEIGA, Ilma P. A. E CASTANHO, Maria Eugênia M. (Orgs.). Pedagogia Universitária: a aula em foco. Campinas-SP: Papirus, 2000, p. 91-113.

BENJAMIN, Walter. O Narrador. In: Magia e Técnica, Arte e Política. Obras Escolhidas. Trad. Sérgio Paulo Rouanet. São Paulo: Brasiliense, 1985. Pp.197-221.

BOM MEIHY, José Carlos S. Manual de História Oral. São Paulo: Loyola, 1996.

BOSI, Ecléa. Memória e Sociedade-lembranças de velhos. São Paulo: Companhia das Letras, 1987.

CANDAU, V. M., ZENAIDE, M.N.T. Oficinas: aprendendo e ensinando direitos humanos. João Pessoa: Programa Nacional de Direitos Humanos. Secretaria da Segurança Pública do estado da Paraíba; Conselho Estadual da Defesa dos Direitos do Homem e do Cidadão, 1999. 
FOERSTE, Erineu. Parceria na formação de professores. São Paulo: Cortez, 2005

GAUTHIER, C. e TARDIF, M. Elementos para uma análise crítica dos modos de fundação do pensamento e da prática educativa. Contexto e Educação, n. 48, Ijuí-RS: UNIJUí, out/dez. 1997. P.37-49.

GAUTHIER, C. Por uma teoria da Pedagogia: pesquisas contemporâneas sobre o saber docente. Ijuí-RS: Unijuí, 1998.

GIROUX, H. Os professores como intelectuais: rumo a uma pedagogia crítica da aprendizagem. Porto Alegre: Artes Médicas, 1997.

LACERDA, Valéria A. D. Professor: a construção da identidade em formação. Estudo de casos e depoimentos de professores alfabetizadores. São Paulo: PUC-SP, 1996, 248 p. (Dissertação de Mestrado em Supervisão e Currículo).

LARROSA, Jorge et al. Déjame que te cuente. Ensayos sobre narrativa y educación. Barcelona: Laertes Editora, 1995.

LIMA, M. S. L. A Hora da prática. Fortaleza: Demócrito Rocha, 2001.

NÓVOA, António (Coord.). Os professores e sua formação. 2 ed. Portugal. Porto: Dom Quixote, 1995.

NÓVOA, António. Vidas de professores. Portugal. Porto: Porto Editora, 1992.

PICONEZ, S. C. B. A prática de ensino e o estágio supervisionado: a aproximação da realidade escolar e a prática de reflexão. PICONEZ, S.C.B. (Coord.). A prática de ensino e o estágio supervisionado. Campinas-SP: Papirus, 1994, p. 13-33.

PIMENTA, Selma Garrido \& LIMA, Maria Socorro Lucema. Estágio e Docência. São Paulo: Cortez, 2004. (Coleção Docência em Formação. Série Saberes Pedagógicos).

QUEIROZ, Maria Isaura P. de. Relatos orais: do "indizível” ao “dizível”. In: VON SIMSON, O. (Org.). Experimentos com histórias de vida: Itália-Brasil. Enciclopédia Aberta de Ciências sociais. São Paulo: Vértice, 1988, p.14-43.

SANTOS, S. M. e ARAÚJO, O. R. de. História Oral: Vozes, narrativas e textos. Cadernos de História da Educação. Uberlândia-MG: EDUFU, n. 6, jan/dez, 2007, pp.191-201.

SANTOS, S. M. Perspectiva e abordagem da História Oral como método. Uberlândia-MG: Universidade Federal de Uberlândia - NEPHE/NEIAPE/FACED, 2010. (Mimeo).

SCHÖN, Donald A. Educando o profissional reflexivo: um novo design para o ensino e aprendizagem. Porto Alegre: Artes Médicas, 2000.

TARDIF, Maurice. Saberes profissionais dos professores e conhecimentos universitários. Elementos para uma epistemologia da prática profissional dos professores e suas conseqüencias em relação à formação para o magistério. Revista Brasileira de Educação. Jan/Fev/Mar/Abr de 2000, n. 13, p. 5-24

VASCONCELOS, Geni A. Nader (Org.). Como me fiz professora. Rio de Janeiro: DP\&A, 2000 .

* Professor doutor da Universidade Federal do Espírito Santo, Vitória, Espírito Santo, Brasil.

** Professora doutora da Universidade Federal de Uberlândia, Uberlândia, Minas Gerais, Brasil. 


\section{Correspondência}

Vilmar José Borges - Universidade Federal do Espírito Santo, Centro de Educação. Avenida Fernando Ferrari - até 845 - lado ímpar, Goiabeiras. CEP: 29075015. Vitória, Espírito Santo, Brasil.

E-mail: vilmar.geo@gmail.com - soniaufu@gmail.com

Recebido em 13 de agosto de 2016

Aprovado em 14 de junho de 2017 
